\title{
Development of a Concept Inventory for Engineering Design Graphics
}

\author{
Mr. Steven Nozaki, Ohio State University
}

PhD Candidate - Engineering Education; The Ohio State University MS, BS - Civil Engineering; The Ohio State University

\section{Dr. Nancy E. Study, Pennsylvania State University, Erie}

Dr. Nancy E. Study is on the faculty of the School of Engineering at Penn State Behrend where she teaches courses in engineering graphics and rapid prototyping, and is the coordinator of the rapid prototyping lab. Her research interests include visualization and haptics. Nancy is a former chair of the ASEE Engineering Design Graphics Division and is currently the Circulation Manager and Treasurer of the Engineering Design Graphics Journal. She received her B.S. from Missouri State University, and M.S. and Ph.D. from Purdue University.

\section{Dr. Heidi M Steinhauer, Embry-Riddle Aeronautical University, Daytona Beach}

Heidi M. Steinhauer is an Associate Professor of Engineering, Department Chair of the Engineering Fundamentals Department, co-advisor for the only all-women's Baja SAE Team, Founding Member of FIRST (Female Initiative Reaching Success Together), and former director for GEMS (Girls in Engineering, Math, and Science). Dr. Steinhauer's awards include the ABET Presidential Award of Diversity and a three time winner of the Women's Vision Award. She has presented papers at ASEE Annual Conference, the ASEE Global Colloquium, Research in Engineering Education Symposium, Engineering Design Graphics Division Mid-Year Conference, Additive Manufacturers Users Group, and Solid Free-Form Fabrication Symposium. Her research interests center around the development and assessment of students' spatial visualization skills, the effective integration of 3D modeling into engineering design, and the impact of contextualized hands-on applications on student learning and success. She has taught Engineering Graphics, Introduction to Engineering Design, Automation and Rapid Prototyping, and has developed several advanced applications of 3D modeling courses. Dr. Steinhauer received her B.S. in Aircraft Engineering and her M.S. in Systems Engineering, and her Pd.D. in Engineering Education from Virginia Tech.

\section{Dr. Sheryl A. Sorby, Ohio State University}

Dr. Sheryl Sorby is currently a Professor of STEM Education at The Ohio State University and was recently a Fulbright Scholar at the Dublin Institute of Technology in Dublin, Ireland. She is a professor emerita of Mechanical Engineering-Engineering Mechanics at Michigan Technological University and the P.I. or co-P.I. on more than $\$ 9 \mathrm{M}$ in grant funding, most for educational projects. She is the former Associate Dean for Academic Programs in the College of Engineering at Michigan Tech and she served at the National Science Foundataion as a Program Director in the Division of Undergraduate Education from January 2007 through August 2009. Prior to her appointment as Associate Dean, Dr. Sorby served as chair of the Engineering Fundamentals Department at Michigan Tech. She received a B.S. in Civil Engineering, an M.S. in Engineering Mechanics, and a Ph.D. in Mechanical Engineering-Engineering Mechanics, all from Michigan Tech. Dr. Sorby has a well-established research program in spatial visualization and is actively involved in the development of various educational programs.

\section{Dr. Mary A. Sadowski, Purdue University, West Lafayette}

Mary A. Sadowski has been at Purdue since 2003 and until September 1, 2011 served as the Associate Dean for Undergraduate Programs and Learning in the Purdue College of Technology where she provided leadership for strategic initiatives in undergraduate education.

As a professor of Computer Graphics, her research interests include enhancing visualization skills, creative thinking, and learning styles. She is currently funded to begin gathering data to create a concept inventory for engineering graphics. As a professor at both Purdue University and Arizona State University, Mary's specialty is computer and technical graphics. Dr. Sadowski received her B.S. from Bowling Green State University, her M.S. from The Ohio State University, and her Ph.D. from Purdue University. 


\section{Dr. Ronald L. Miller, Colorado School of Mines}

Ronald L. Miller is a professor emeritus of chemical engineering and former Director of the Center for Engineering Education at the Colorado School of Mines, where he has taught chemical engineering and interdisciplinary courses and conducted engineering education research for the past 30 years. Miller has received three university-wide teaching awards and has held a Jenni teaching fellowship at CSM. He has received grant awards for education research from the National Science Foundation, the U.S. Department of Education FIPSE program, the National Endowment for the Humanities, and the Colorado Commission on Higher Education and has published widely in engineering education literature. His research interests include measuring and repairing engineering student misconceptions in thermal and transport science. 


\title{
The Development of a Concept Inventory for Engineering Graphics
}

\begin{abstract}
This work in progress describes the development of a concept inventory for Engineering Graphics. As instructional methods continue to evolve in the area of graphics, there is a need for a concept inventory instrument that is able to measure the students' understanding of important graphical concepts and the presence of robust misconceptions. This paper is a work-in-progress describing the status of the development of such an instrument. Details documenting the evolution of a representative inventory item will be highlighted in this paper.
\end{abstract}

\section{Introduction}

In the early days of engineering education, students completed one or two years of drafting training as part of their curriculum. At the time, this made sense because it was engineers who created the drawings and other documentation needed to construct or manufacture their designs. Gradually, drafting became the job of technicians as engineers focused on the more complicated aspects of engineering analysis; however, engineers remained principally involved in the creation of the design documentation by checking and verifying the objects and systems that appeared on the blueprints. Today's engineers spend a good deal of their time developing computer models of their designs in cooperation with teams that include technicians, machinists, and others as needed in the engineering enterprise.

As drafting became less prominent for engineering professionals, graphics courses decreased in prominence within the curriculum. In 1974, the engineering accrediting agency (precursor to ABET) eliminated the graphics requirement and graphics began to be deemphasized or eliminated from engineering programs across the country ${ }^{1}$. In some cases, engineering disciplines such as electrical or chemical engineering, opted out of graphics requirements entirely. Today, most engineering programs have one semester or less of graphics instruction. Due to the reduction of graphics within the engineering curriculum, it is important that the graphics that we do teach is grounded in the fundamentals.

Teaching methods in engineering graphics are ever changing; as technology advances, so do the means by which engineering students learning this form of communication. Often, the instruction is centered on the methods of creating graphics instead of the underlying concepts. While it is important to stay relevant in regards to current technologies, it is also important to keep in context the concepts that serve as an 
underpinning for the methods being employed. It is generally agreed that students should have a certain level of proficiency in standard practices upon completion of a graphics course of study. However, the topics being considered as part of this foundation are not quite as agreed upon. This lack of consensus can lead to nonconformities in educational practices, and decreased effectiveness in graphics education.

\section{Background}

A concept inventory is an instrument that helps faculty identify the concepts that their students do not understand and decide which misconceptions are the most prevalent. Concept Inventories are also used to identify important topics for a course and to aid instructors as they assess the educational outcomes from their specific course. The first concept inventory was the Force Concept Inventory developed and implemented by Hestenes. It was developed as a test to identify students' misconceptions about Newtonian Force ${ }^{2}$. Since the successful implementation of the Force Concept Inventory, there has been a strong interest in developing concept inventories for other STEM fields. The NSF-funded Foundation Coalition headed by D. D. Evans at Arizona State began working on developing Concept Inventories in the engineering disciplines in 2000. In the intervening years, a variety of concept inventories have been developed, including: materials, statics, heat transfer, chemistry, computer engineering, dynamics, and electronics.

The Coalition stated in 2003 that 'for the most part teaching of engineering subjects continues to be patterned after how instructors were taught when they were students of the subject rather than being informed by research of learning”3. They contended that reform in Science, Technology, Engineering and Math (STEM) education is hampered partially due to the lack of good assessment instruments. Once implemented, the Force Concept Inventory assessment designed by Hestenes et. al. ${ }^{2}$, stimulated a variety of reforms in physics education. "Such assessments can play an important part in relating teaching techniques to student learning." ${ }^{3}$ It is anticipated that the development of a concept inventory for engineering graphics will result in similar reforms in graphics courses, where instructors will recognize the value of instruction that focuses on fundamentals rather than the "tool of the day."

Concept inventories are instruments used to identify misunderstandings and misconceptions regarding a set of related conceptual ideas. Misconceptions are deeply rooted beliefs, and overcoming them can be problematic for instruction. To address these misconceptions, the constructs that students are having difficulty with need to be identified. The use of a quality concept inventory may provide instructors with such data. The common format of a concept inventory is a multiple-choice examination consisting of items focused on each key concept. A stem (question) is presented to the student that relates to a particular conceptual construct. The choices for answers contain a correct answer, and several alternative incorrect answers, or distractors. These distractors often are solutions based on common misconceptions, allowing one to make inferences into areas where students' competencies reside. Currently, there is 
no instrument that can be used in graphics courses to assess these types of misconceptions. Work by the project team thus far has been toward the development of such an instrument and our progress to date is summarized in this paper.

\section{Framework for Creating the Graphics Concept Inventory}

The graphics concept inventory is being developed using the "assessment triangle" model depicted in Figure 1. This model was proposed by a National Research Council panel of assessment experts who suggested that three interrelated elements must be addressed to create a high quality assessment instrument ${ }^{4}$. These elements focus on cognition, observation, and interpretation elements as defined by Streveler ${ }^{5}$ :

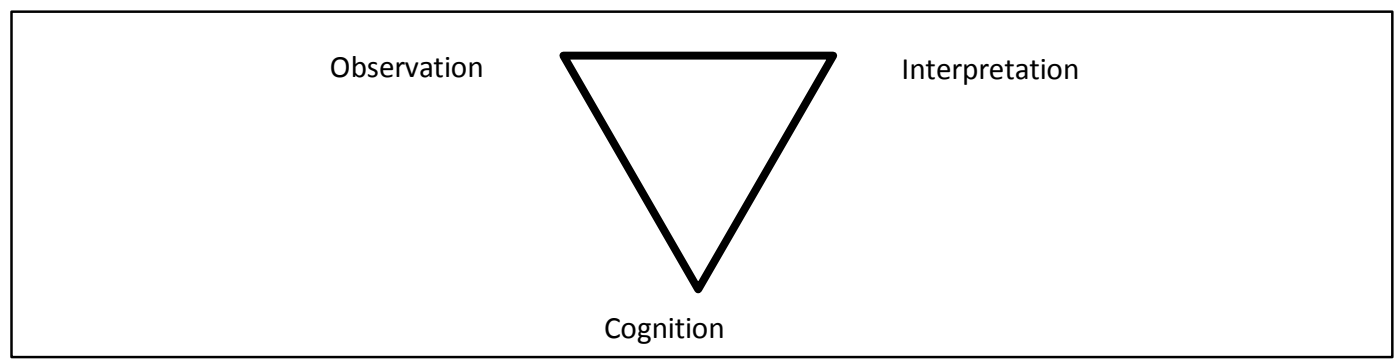

Figure 1. Assessment Triangle (adapted from Pellagrino ${ }^{4}$ )

- "The cognition corner of the triangle refers to 'a theory or set of beliefs about how students represent knowledge and develop competence in a subject domain'4. The domain of interest is referred to as the target domain. In other words, the cognition corner takes into account how the students learn about the target domain. When addressing the cognition corner one could consider misconceptions students might have about the target domain, developmental trajectories as students gain expertise, common errors that are made, etc.

- The observation corner 'represents a description or set of specifications for assessment tasks that will elicit illuminating responses from students' about the target domain to be measured ${ }^{4}$. Simply said, the observation corner represents the kinds of tasks that will make up the assessment itself. The assessment tasks that are chosen should make sense with respect to the cognition corner. For example, if one is interested in measuring higher-level thinking then the tasks on the assessment should require that higher-level thinking be exhibited.

- The interpretation corner 'encompasses all the methods and tools used to reason from fallible observations' that have been made in response to the tasks defined by the observation corner of the triangle ${ }^{4}$. We might also say that the interpretation corner focuses on what we make of, or how we interpret, the results of the assessment tasks. Thus the interpretation corner guides us in choosing analysis methods appropriate for the tasks that have been created in the observation corner." 
To be effective, development of a concept inventory like the Graphics Concept Inventory must involve aligning the three assessment corners. This means that beliefs about how students learn the target domain must be consistent with the kinds of assessment tasks that are created and with the methods used to analyze the results of the assessment. The interpretation of assessment results can then provide valuable information about how students learn the target domain, which is the underlying purpose of developing and using the concept inventory. More details about how each corner of the assessment triangle informs concept inventory development have been published $^{5}$.

\section{Process to Date}

\section{Delphi Study}

In a previous project, a Delphi Study was conducted to help identify core topics in engineering graphics. The Delphi Technique, in which regarded experts on a subject are consulted collectively, was used ${ }^{6,7}$.

The first round took place at a workshop consisting of graphics professionals and resulted in a total of 120 unique topics. An expert panel of industry representatives, high school, community college, and university professionals was convened for the final three rounds. Through the Delphi process the 120 topics were reduced to 37 unique topics that coalesced to 10 concepts (Table 1), which served as the constructs for the development of an engineering graphics concept inventory.

\begin{tabular}{|c|c|}
\hline Visualizing in 2D and 3D & Projection Theory \\
\hline Mapping between 2D and 3D & Parallel Projection Methodologies \\
\hline Planar Graphical Elements & Drawing Conventions \\
\hline Sectional Views & Dimensioning \\
\hline Methodologies for Object Representation & Solid Modeling Constructs \\
\hline
\end{tabular}

Table 1: Concepts Identifyed by Dephi Study ${ }^{6}$

\section{Pilot Study}

In order to reinforce consistent communications, weekly conference calls were scheduled with team members. Using the concepts identified in the Delphi Study as a basis, work on item creation began. Discussions between the project personnel provided collective guidance for drafting the pilot questions. These questions were intended to address only one concept whenever possible. An open-ended format was selected for the pilot questions in order to better observe the conceptions held by participants, who were all students enrolled in introductory engineering graphics courses at three different universities. Most of the students represented were engineering students; however, for 
one of the schools participating, engineering technology students were examined. The questions generally required participants to provide a response in the form of a sketch. Administering open ended questions generated formative feedback in two areas. The first was that subjects' answers could provide a wealth of information from which to create potential distractors, because patterns in the responses would reveal trends in student misconceptions. The second area was related to item structure because subjects were encouraged to comment on the format of the questions, making note of interpretations and possible errors. This would later help the revision process by highlighting any issues with how the items were presented.

A total of 60 pilot items were drafted. Before the pilot test was administered, twelve students in a senior level graphics and modeling course at one of the participating universities were asked to review the items, give feedback on clarity of the questions, and note any possible typos or mistakes in the graphics. These students did not provide responses to the questions. Because it was late in the semester and course instruction had already been planned at each participating institution, not all 60 items could be tested on every student participant due to classroom time constraints. The items were compiled into different sized packets based on the time available for testing at each participating institution. A testing protocol was established by the group so all packets in the pilot study were administered in a uniform fashion.

Pilot responses from all institutions were collected and the results aggregated. The responses were coded by the researchers to look for misconception trends. Before coders were allowed to individually code items, a satisfactory inter-rater reliability was established between multiple reviewers and the research team. This was accomplished by looking at the student responses and determining specifically what would make a response correct or incorrect based on what concept the question was testing. Examples of an open ended question from the pilot study (Figure 2), the expected solution (Figure 3), and a sample of an incorrect student response (Figure 4) are shown. Students were also asked to rate each question using a Likert scale indicating whether or not they understood what the question was asking, and where they considered the question's difficulty to lie on a scale from very easy to very difficult.

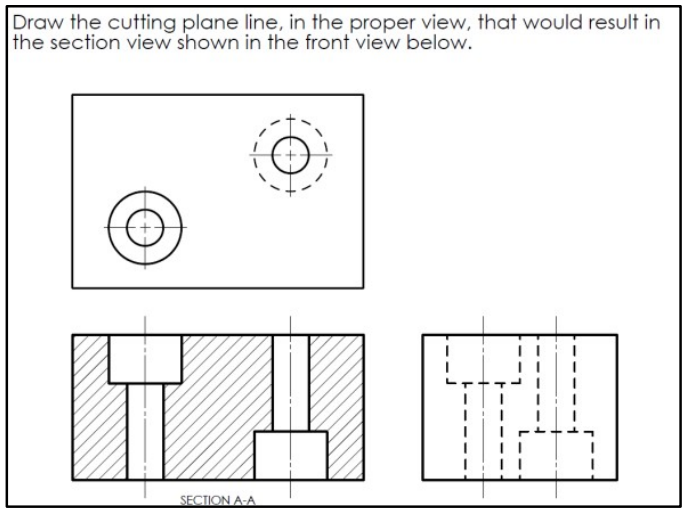

Figure 2: Example Open Ended Pilot Study Item 


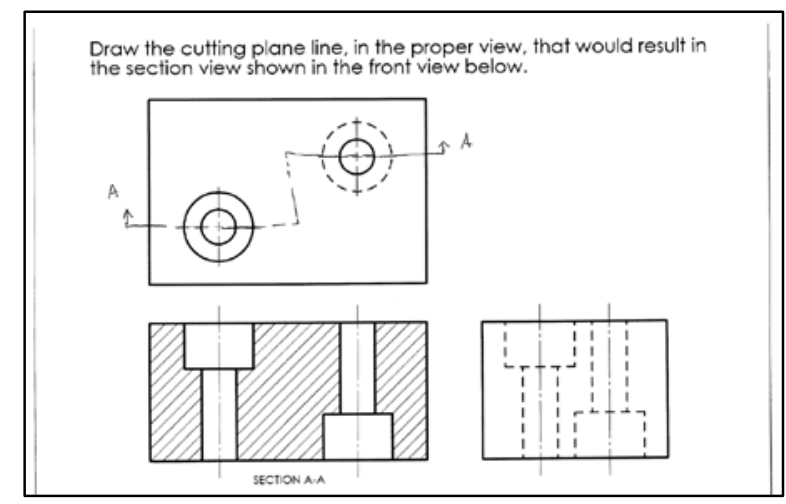

Figure 3: Intended Correct Solution for Pilot Item

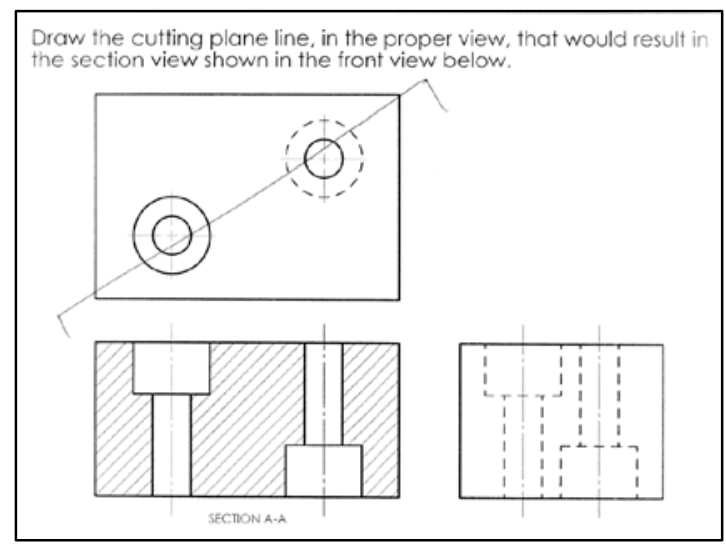

Figure 4: Example Open Ended Participant Incorrect Response

\section{Drafting Distractors}

With the data from the pilot study coded, work could begin on the drafting of potential distractors. In a similar collective effort to what was used to create the pilot study items, researchers reviewed the data from the pilot study to begin the work on drafting distractors. At this point, items that had received overwhelmingly correct responses were set aside with the reasoning that easy items would not be able to differentiate misconceptions in a final version of the concept inventory.

Additionally, items that had responses with little to no useful pattern were also set aside, although having responses with no distinct trends did not mean the item was totally without use. For the items with exceptionally unusable responses, we discerned that the issue was more likely attributed to the item prompt than to the concept addressed in the question itself. Plans were made to revisit items with problematic prompts once the other distractor drafts were completed.

The group collectively wrote potential distractors for each item using open- ended student responses as a guide and then as a full group, selected the three most appropriate 
distractors (items will be multiple choice with 4 possible answers so three distractors are needed per item). The selected distractors were typically similar to the three most prevalent incorrect coded responses from the pilot study. In cases where there were not enough significant options developed from the pilot study, the team worked together to create distractors that were inspired by responses and the vast experience of the research team in teaching engineering graphics for a collective $70+$ years.

\section{Current Status}

The research team is currently making revisions to the items that will be included in a preliminary version of a multiple choice instrument. Once the distractors have been selected for the remaining items, they will be created electronically and consistently formatted. The administration will be done in a manner similar to the pilot study. In accordance with the time allotments granted by participating institutions, appropriately sized test instruments (typically 10-20 items) will be assembled and distributed. To maximize versatility and application, the instrument will be compiled electronically using a platform that is independent of institution specific learning management systems. This will hopefully allow for increased distribution amongst participating institutions, more versatility in data collection and analytics, and being better able to address administrative issues from a central standpoint. In particular, the consolidated administrative management is of particular appeal to the group. For example, participating institutions with differing lecture durations may permit differing amounts of items to be tested at a time. Another example would be that item count may could be more uniformly controlled, as items relating to particular constructs could be paid increased attention. Conceivably, a completed version will also have to be administered and assessed to assess the instrument as a whole, and not just particular items.

Once responses from the initial testing of distractors are compiled, statistical methods will be used to determine item and distractor attributes. Item Response Theory and Classical Test Theory will be the basis for analyzing the pilot data. It is the intent to have a range of abilities be measured by the completed instrument, and not just the categorization of high performers. It is of importance to the study that items with high discrimination and reliability be included in later versions of the instrument. This will help to ensure cogency and ultimate usefulness of the instrument. Preference for item inclusion will also be given to those items that best isolate individual constructs. When considering the work that has been done thus far on the project, it is a possibility that items do not wholly and uniquely address an isolated construct. The work on the study thus far has shown that while this may be a possibility, it is not beyond reason to be able to further distill items and distractors to an acceptable level. 


\section{Conclusions}

The work in the development of a concept inventory for engineering graphics has yielded valuable insights thus far. The phenomenon of expert-blind-spots has been revealed numerous times in the creation and evaluation of pilot items. This occurs when practitioners reach a high enough level of proficiency that it impedes their ability to relate to beginner mistakes. Items whose inclusion in the pilot study were questioned by one or more researchers tended to generate a range of unexpected responses. There were several responses that seemed beyond the comprehension of the researchers, as it seemed so against what was ingrained in graphics convention and practice.

\section{References}

1 Pleck, M. H., Mcgrath, M. B., Bertoline, G. R., Bowers, D. H., \& Sadowski, M. A. (1990). Factors Affecting the Engineering Design Graphics Curriculum: Past, Present, Future. Proceedings of the NSF Symposium on Modernization of the Engineering Design Graphics Curriculum, Austin, TX, August 1990, pp. 43-52.

2 Hestenes, D., Wells, M., \& Swackhamer, G., (1985). The Initial Knowledge State of College Physics Students. The Physics Teacher Vol. 30, (March 1992), pp. 141-158.

3 Evans, D. L., Gray, G. L., Krause, S., Martin, J., Midkiff, C., Notaros, B. M., Pavelich, M., Rancour, D., \& Reed-Rhodes, T., Progress on concept inventory tools. In $33^{\text {rd }}$ ASEE/IEEE Frontiers in Education Conference Proceedings, (Nov. 2003), Boulder, CO, pp. T4G1-T4G8. J. Pellegrino, N. Chudowsky and R. Glaser, Knowing What Students Know: The Science and Design of Educational Assessment, National Academy Press, Washington, DC, 2001.

5 Streveler, R.A., Miller, R.L., Santiago Roman, A.I., Nelson, M.A., Geist, M.R., \& Olds, B.M. (2011). Using the “assessment triangle” as a framework for developing concept inventories: A case study using the thermal and transport concept inventory. International Journal of Engineering Education, 27 (5), 1-17.

6 Sadowski, M.A., Sorby, S.A. (2013). Update on a Delphi Study for Developing a Concept Inventory for Engineering Design Graphics, Engineering Design Graphics Division $68^{\text {th }}$ MidYear Meeting Proceedings, Worchester, MA.

7 Sadowski, M.A., Sorby, S.A. (2015). Engineering Graphics Concepts: A Delphi Study. ASEE Annual Conference Proceedings, Seattle, WA. 